\section{Human insulin}

SIR,-We were interested to read the recent leading article by Dr John Pickup (18 January, p 155). The enthusiasm resulting from the technological achievement of producing human insulin by recombinant DNA techniques needs to be tempered by a degree of realism about its clinical advantages over more conventional insulin preparations.

There is little doubt that human insulin is less immunogenic than porcine or bovine insulin, but Dr Pickup goes further and states that the development of insulin antibodies is associated with impaired endogenous insulin secretion and a shortened remission period in newly diagnosed insulin dependent diabetics. We have presented data which suggest that this is not the case.

Thirty nine newly diagnosed patients with insulin dependent diabetes were randomly allocated in a double blind study to treatment with human (emp), purified porcine, or purified bovine insulin. At six months there was no significant change in insulin antibody concentrations in the human and porcine groups but a significant increase in the bovine group from a mean of $4.6 \mu \mathrm{g} / \mathrm{l}$ to $31.3 \mu \mathrm{g} / \mathrm{l}(\mathrm{p}<0.01)$. However, there was no reduction in either basal or glucagon stimulated C peptide secretion. Indeed, the group treated with bovine insulin had slightly higher $\mathrm{C}$ peptide values than the other two. Basal $C$ peptide values at six months were (mean and $S D$ ): bovine $0.23(0.09) \mathrm{nmol} / \mathrm{l}$, porcine $0.17(0.08) \mathrm{nmol} / \mathrm{l}$, and human $0.18(0.10) \mathrm{nmol} / \mathrm{l}$ (bovine $v$ porcine/ human, $\mathrm{p}<0.05$ )

Our study showed that moderate increases in insulin antibody concentrations do not reduce residual endogenous insulin secretion. Whatever advantages human insulin may have over porcine or bovine insulin, treatment with it is unlikely to lengthen the remission phase of insulin dependent diabetes.

Queen Elizabeth Hospital

S A OLCZAK

Birmingham B15 2TH

Norfolk and Norwich Hospital,

Norwich

1 Olczak SA, Rainbow S, Murphy M, Dalrymple J, Patrick D, Greenwood RH. Insulin antibodies do not reduce residual C-peptide secretion in newly diagnosed IDDM. Diabetic Medicine 1985;2:218A.

\section{Role of computed tomography in assessing "operability" of bronchial carcinoma}

SIR,-Dr P T Doyle and colleagues (25 January, p 231) suggest that inoperability of bronchial carcinoma can be assessed accurately from computed tomography alone. The reliability of this conclusion, however, is thrown into doubt by their failure to compare the findings of computed tomography directly with those of surgical exploration in all patients. They themselves point out the problem of interpreting nodes enlarged because of reactive hyperplasia and differentiating them from nodes containing tumour.

Indeed, in this study 47 patients were deemed inoperable on findings of computed tomography alone. These patients have been denied a potentially curative resection without confirmation of these findings by mediastinoscopy. On the other hand, 25 patients underwent unnecessary thoracotomy. They showed evidence on computed tomography of possible spread of mediastinal tumour and should certainly have undergone mediastinoscopy before being subjected to thoracotomy.

The authors have recommended a modified series of investigations for patients with potentially resectable lung cancer without having validated this approach. We strongly disagree with their recommendations and would suggest that mediastinal spread indicated by computed tomography should be confirmed histologically in all cases. There are numerous published reports on mediastinal staging in lung cancer to support our standpoint. ${ }^{1-5}$

ROBERT MILROY JAMES H MCKILLOP STEPHEN W BANHAM KenNETH G DavidSON

Belvidere Hospital,

Glasgow G31 4PG

1 Bryer RH, Karstaedt N, Mills SA, et al. Computed tomography for evaluation of mediastinal lymph nodes in lung cancer: correlation with surgical staging. Ann Thorac Surg 1984;38: 215-20.

Rea HH, Shevland JE, House AJS. Accuracy of compure tomographic scanning in assessment of the mediastinum in bronchial carcinom 7 Thorac Cardionasc Surg 1981:81:825-9.

Goldstaw P, Kurzer M, Edwards D. Pre-operative s1:825.9. lung cancer: accuracy of compu

4 Richey HM, Matthews JI, Helsel RA, Cable H. Thoracic CT Scanning in the staging of bronchogenic carcinoma. Chest 1984;85:218-21

5 Milroy R, Smith L, Faichney A, et al. Mediastinal imaging in lung cancer. Thorax 1985;40:209.

${ }_{*}^{* *}$ The authors reply below.-ED, $B M \mathcal{F}$

SIR,-We strongly refute the criticisms of $\mathrm{Dr}$ Milroy and colleagues. Early in our series we performed nine mediastinoscopies for paratrachea lymphadenopathy, and positive nodes were found in all cases. Mediastinoscopy is, however, an inappropriate investigation for subcarinal, sub aortic, and azygo-oesophageal lymphadenopathy and for direct mediastinal invasion below the level of the azygos vein. As our series has progressed there is now only a $1 \%$ false positive rate, and we believe that this is a small price to pay for diminishing the morbidity from failed thoracotomy, which at one time accounted for $20-30 \%$ of all attempts at resection of bronchial carcinoma The presence of nodal metastases confers such a poor prognosis, even in resectable tumours, that a case can be made for treatment other than surgery.

We also think that a simple non-invasive technique is preferable to an unnecessary thoracotomy and that the quality of life in the patient with an inoperable bronchial carcinoma is better if he or she does not have to recover from irresponsible surgery. We appreciate that it is difficult for clinicians in many centres to obtain access to computed tomography, but the main point of our paper is to show that computed tomography should be a standard investigation before thoracotomy in all patients with bronchial carcinoma. Our experience over the past five years is supported by similar results from other units where there is a close liaison between departments of thoracic surgery and radiology

We have no doubt that in our hands computed tomography has proved a major advance in caring for patients with bronchial carcinomas.

J WEIR

EllizabeTH M ROBFRTSON A V FOOTE

Aberdeen Royal Infirmary

J S COCKBURN

Aberdeen AB9 2ZB

\section{Ventricular assist devices}

SIR, - The timely leading article by Dr Brian Glanville and Mr Donald Ross (8 February, p 361) highlights the importance of considering the cost implications of this advanced technology. In this context I think it is worth emphasising the known efficacy of available, less expensive pumps in the management of patients who cannot be weaned from cardiopulmonary bypass. The morbidity of left heart bypass conducted using roller or centrifugal pumps has been substantially reduced by modification of the anticoagulation protocols previously used, and application of a centrifugal pump without anticoagulation for postoperative left ventricular assist is a major clinical advance.'

In view of escalating costs it seems appropriate, therefore, that ventricular assist devices should primarily be used in patients requiring long term mechanical circulatory support. Simpler and less expensive technology may be equally effective in patients requiring short term support after cardiac surgery.

The Hospital for Sick Children,

B SETHIA

Great Ormond Street,

London WC1N 3JH

1 McGovern DJ, Park SB, Maher TH. Use of a centrifugal pump without anticoagulants for post operative left ventricular assis World f Surg 1985;9:25-36.

\section{Occupationless health}

SIR,- May I congratulate you for publishing and Dr Richard Smith for researching and writing one of the most valuable studies on a medicosocial subject yet seen in the medical literature. As the title of his final article indicates, improving the health of the unemployed really is a job for health authorities and health workers. Pace Dr J W Maltby (15 February, p 488), this series fully justifies the space you have found for it.

Medical care is not a technical service standing by itself; health care is a part of a much wider spectrum of social welfare for which the legislation of the 1940s sought to provide. I have little doubt that the great majority of our profession recognises that we have not only a citizen's concern for the present national calamity of one seventh of the workforce condemned to idleness by factors outside their control but also a duty to provide what relief we can for the ill health that Dr Smith has shown results from it.

Cambridge CB1 4NZ

GEORGE GODBER

SIR,-Dr Richard Smith's series has underlined the lack of knowledge of "how unemployment harms families"-knowledge, as he says, that is wanting in "the degree of proof that reluctant politicians demand before they will take action."

In classical literature writers were fully persuaded of the wellbeing and other benefits conferred by work and of the drawbacks linked to not working. In Candide Voltaire wrote that "work banishes those three great evils, boredom, vice, and poverty." In Thomas Carlyle's rectorial address at Edinburgh University (given a century ago) he maintained that "work is the grand cure of all the maladies and miseries that ever bese mankind." In Tolstoy's War and Peace, when Prince Andrei asked his father "How is your health?" the latter replied briskly, "Only fools and rakes ever need to be ill, my boy, and you know me-abstemious, and busy from morning til night, so of course I'm well."

Dr Smith said in one of his early articles (23 November, p 1493), "It has not been proved that unemployment kills." Yet in a particular context of enforced unemployment there is evidence that the mortality rate from coronary heart disease may double within a year of a man's retirement from work.

If segments of the population, not specifically those wholly unemployed but those among whom unemployment is far higher than the average, 